\title{
Thermo-Dynamics and Stress Characteristics on High Strength Hydraulic Concrete Material
}

\author{
Xiao-Qing Gan ${ }^{1,2}$ and Ya-jun Wang, 3 ,* \\ ${ }^{I}$ State Key Laboratory of Water Resources and Hydropower Engineering Science, Wuhan University, Wuhan, Hubei \\ 430072, P.R. China \\ ${ }^{2}$ Yangtze River Scientific Research Institute, Wuhan, Hubei 430010, P.R. China \\ ${ }^{3}$ School of Maritime and Civil Engineering, Zhejiang Ocean University, Zhoushan, Zhejiang 316000, P.R. China
}

\begin{abstract}
High strength hydraulic concrete was introduced based on its thermo-dynamic and strain-stress characteristics. The compound exponential thermo-dynamic creep model was established. The temperature rise models were interpreted. The bisection constitutional model was deduced as the approach to express the strain-stress non-linearity of high strength hydraulic concrete. The key parameters on thermo-dynamic characteristics and strain-stress ones of high strength hydraulic concrete were offered. The models and parameters in this paper are useful for engineering application and theoretical research.
\end{abstract}

Keywords: High strength hydraulic concrete, non-linear model, thermo-dynamics.

\section{INTRODUCTION}

High strength and fully graded concrete has been the predominant material for Sino hydraulic structures. Therefore, these monstrous structures' working behaviors are controlled mainly by the mechanic characteristics of the massive concrete materials.

Unfortunately, the comprehensive study on concrete found in Sino-mainland was abated by the overwhelming construction work.

The target concrete material in this paper was produced in State Key Laboratory of Hydroscience and Hydraulic Engineering of Tsinghua University. All these parental materials including gravel, sand, cement and silica fume etc. were achieved in the construction site of South-Western China. The concrete's constituents' percentages are shown in detail in Fig. (1) where the values are mass percentages. The sand and gravel were taken from Jinshajiang River catchment where the main lithologic character is basalt layer; the range of gravel size is $5-20 \mathrm{~mm}$ and the relative compaction value of sand is 0.35 (M. Bravo and J. de Brito, 2012) [1]; the water used here is Northern China pure water which can be applied instantly for lives and the ph is 7.0; the moderateheat cement powder is produced by South-Western China Xuanwei producer and the grade is 425 of Sino-mainland standard; the fly-ash powder is produced by Nantong Haichuang producer in Jiangsu Province and its application can depress effectively the hydration heat generation, especially during the early stage of concrete pouring procedure

*Address correspondence to this author at the School of Maritime and Civil Engineering, Zhejiang Ocean University, Zhoushan, Zhejiang 316000, P. R. China; Tel: +86580 255 0008; E-mail: aegis68004@yahoo.com.cn
(J. S. Ryou and Y. S. Lee, 2012) [2]; the producer for silica fume used here is Langtian Company of Sichuan Province in South-Western China and silica fume will increase the strength of concrete material (X. Y. WANG, 2013) [3]; the water reducing agent is the tripolycyanamide series produced by Xiangbang company in Jiangsu Province, and it is the indispensable addition here because it decreases the water supplement while the silica fume is used (M. Nili and V. Afroughsabet, 2012) [4]; the air entraining agent, which can densify the concrete, is colophony one produced by Qicheng company in Shanghai.

The high strength concrete were poured and modeled into normal samples for the creep loading test. The normal concrete samples' dimension (i.e., length, width and height) are $100 \mathrm{~mm} \times 100 \mathrm{~mm} \times 300 \mathrm{~mm}$. C40 samples are the study targets in this paper where $\mathrm{Cn}$ designates the concrete strength grade in Sino-mainland and the unit for grade $n$ is MPa.

\section{THERMO-DYNAMIC CHARACTERISTICS ON HIGH STRENGTH HYDRAULIC CONCRETE}

Especially, these hydraulic structures are often undermined by influential temperature creep deformation during the long, uncertain and sinister construction period $(\mathrm{Q}$. WANG et al., 2011; Z. W. LI et al., 2012) [5, 6]. The temperature cracks in hydraulic concrete material and structures will incur hazardous damage in the development which may be an overwhelming disaster for the whole catchment. Some typical temperature cracks on the concrete surface from Sino hydraulic structures are shown in Fig. (2).

The key technique for temperature cracks control is the quantification on thermo-dynamic parameters and models of the high strength concrete. The key thermo-dynamic subjects on temperature cracks control of concrete material are the 


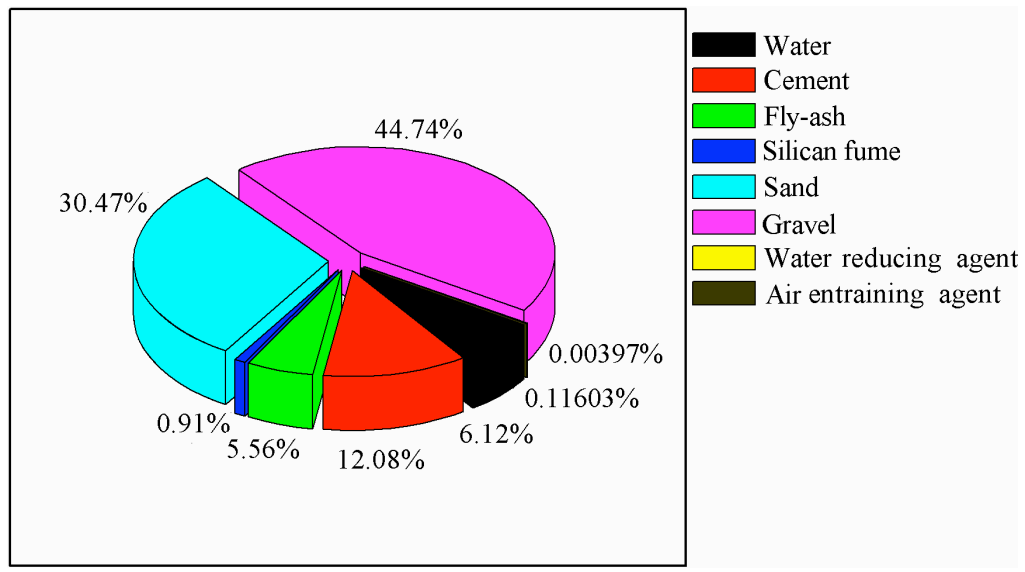

Fig. (1). High strength hydraulic concrete constituents (with mass percentages).
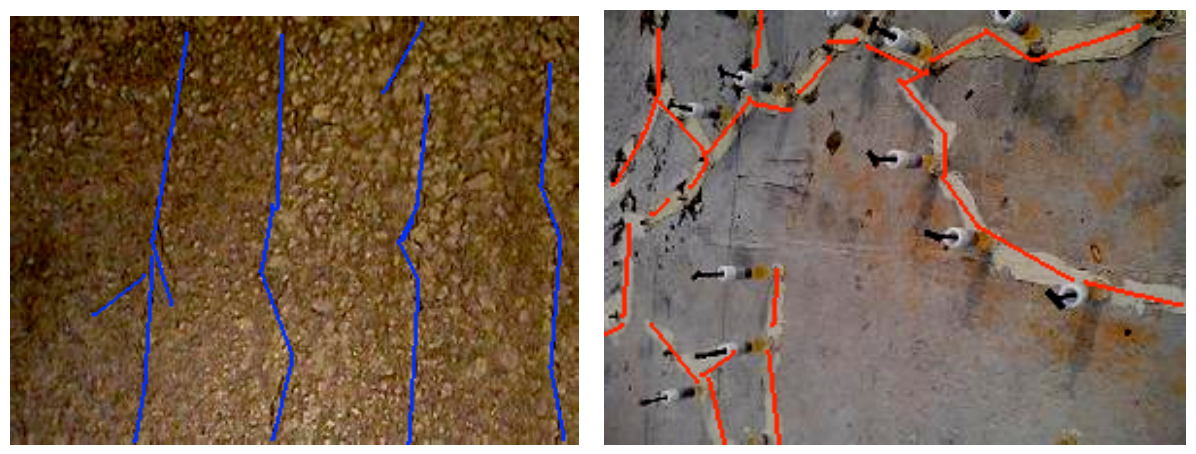

Fig. (2). Typical temperature cracks on the surface of hydraulic concrete structures.

thermo-dynamic creep models and temperature rise models. The generally acceptable thermo-dynamic creep model in Sino-hydraulic research is the compound exponential model. The merits of the compound exponential thermo-dynamic creep model are that it can unitize the thermo-dynamic simulation on the recoverable creep and unrecoverable creep. The compound exponential thermo-dynamic creep model can be expressed as Eq.1.

$$
\begin{aligned}
& C(t, \tau)= {\left[A_{0}+A_{1} \cdot \tau^{\left(-A_{2}\right)}\right] \cdot\left[1-e^{-m_{1} \cdot(t-\tau)}\right]+} \\
& {\left[B_{0}+B_{1} \cdot \tau^{\left(-B_{2}\right)}\right] \cdot\left[1-e^{-m_{2} \cdot(t-\tau)}\right]+} \\
& D \cdot e^{\left(-m_{3} \cdot \tau\right)} \cdot\left[1-e^{-m_{3} \cdot(t-\tau)}\right]
\end{aligned}
$$

where, $C(t, \tau)$ refers to the concrete's thermo-dynamic creep value; $\tau$ is the static age from the curing start point; $t$ is the total age which includes the static age and loading period; $A_{0}, A_{1}, A_{2}, B_{0}, B_{1}, B_{2}, m_{1}$ and $m_{2}$ are the fitting parameters on concrete material's early stage recoverable creep; $D$ and $m_{3}$ are the fitting parameters on concrete material's maturely unrecoverable creep; $t-\tau$ represents the loading duration increment.

Fig. (3) shows the normal concrete sample and creep loading test. As for the samples with the age of $7 \mathrm{~d}$ or $28 \mathrm{~d}$, the eventual creep loading duration increment is $200 \mathrm{~d}$ that is the generally acceptable test standard on concrete creep test in

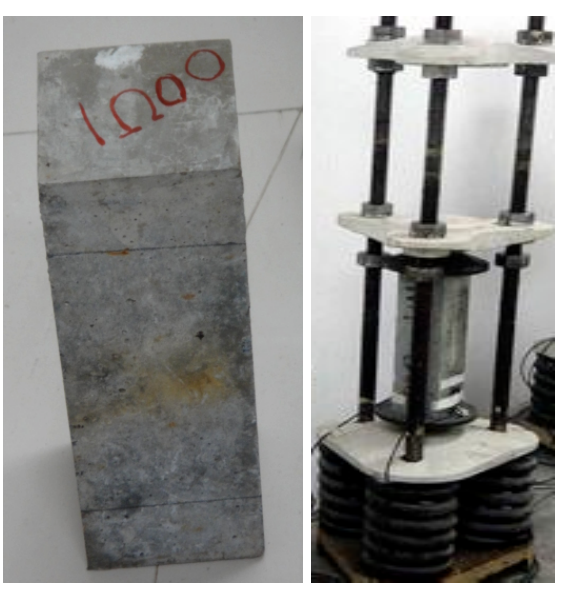

Fig. (3). Concrete creep loading test and concrete sample.

Sino-mainland. The instrument for concrete creep test is TXB- 50 system produced by Gangyuan company in Tianjin.

Concrete creep measured data are shown in Tables $\mathbf{1}$ and 2 where the numerical fitting results are also offered.

The numerically fitted curves on creep measured data of high strength hydraulic concrete are shown in Fig. (4).

It can be deduced from the creep loading test results on high strength concrete that the longer the curing age is, the lower the creep value is. According to most studies on high concrete materials, the curing activities are the key to 


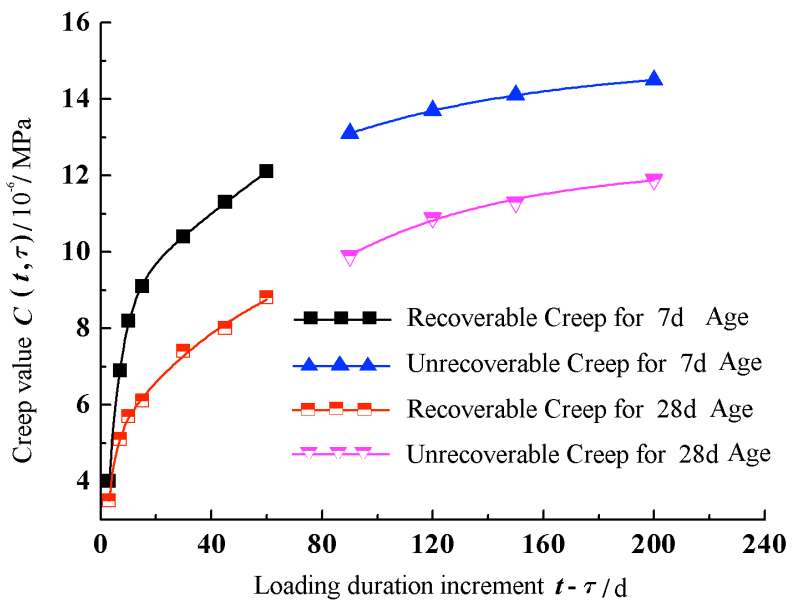

Fig. (4). Measured data and fitted curves from concrete creep loading tests on high strength hydraulic concrete.

reduce the creep value level. The frequent curing can also restrain the development of temperature cracks.

The hydration heat is the intrinsic character of concrete material and it is the main cause of temperature cracks in hydraulic concrete material and structures. Therefore, the proper quantification for the hydration heat is the key technique for temperature cracks control on high strength hydraulic concrete. The temperature rise model can quantify numerically the magnitude of the hydration heat, especially during the dangerous period of concrete pouring. There live four temperature rise models in Sino hydraulic concrete thermo-dynamics, namely, power-exponential composite model, hyperbolic model, single-exponential model and double-exponential model. These models' functions are as follows:

$$
\begin{aligned}
& T=T_{0}\left(1-e^{-a t^{b}}\right) \\
& T=\frac{28 t}{t+2.58} \\
& T=T_{0}\left(1-e^{-a t}\right) \\
& T=T_{\mathrm{e}}\left(1-e^{-c t}\right)+T_{1}\left(1-e^{-d t}\right)
\end{aligned}
$$

\begin{tabular}{|c|c|c|c|c|c|c|c|}
\hline \multirow{2}{*}{$\begin{array}{c}\begin{array}{c}\text { Loading Duration } \\
\text { Increment for Recov- } \\
\text { erable Creep/d }\end{array} \\
\text { - }\end{array}$} & \multirow{2}{*}{$\begin{array}{c}\begin{array}{c}\text { Recoverable Creep Val- } \\
\text { ue } / 10^{-6} / \mathrm{MPa}\end{array} \\
4\end{array}$} & \multicolumn{2}{|c|}{ Fitted Parameters } & \multirow{2}{*}{$\begin{array}{c}\text { Loading Duration } \\
\text { Increment for Unre- } \\
\text { coverable Creep/d }\end{array}$} & \multirow{2}{*}{$\begin{array}{c}\begin{array}{c}\text { Unrecoverable Creep } \\
\text { Value } / \mathbf{1 0}^{-6} / \mathbf{M P a}\end{array} \\
13.1\end{array}$} & \multicolumn{2}{|c|}{ Fitted Parameters } \\
\hline & & $A_{0}$ & 1.99 & & & $D$ & 17.31437 \\
\hline 7 & 6.9 & $A_{1}$ & 19.81 & 120 & 13.7 & $m_{3}$ & 0.02545 \\
\hline 10 & 8.2 & $A_{2}$ & 0.703 & 150 & 14.1 & & \\
\hline 15 & 9.1 & $B_{0}$ & 3.97 & 200 & 14.5 & & \\
\hline 30 & 10.4 & $B_{1}$ & 11.89 & & & & \\
\hline 45 & 11.3 & $B_{2}$ & 1.495 & & & & \\
\hline \multirow[t]{2}{*}{60} & 12.1 & $m_{1}$ & 0.0892 & & & & \\
\hline & & $m_{2}$ & 0.10801 & & & & \\
\hline
\end{tabular}

\begin{tabular}{|c|c|c|c|c|c|c|c|}
\hline \multirow{2}{*}{$\begin{array}{c}\begin{array}{c}\text { Loading Duration } \\
\text { Increment for Recov- } \\
\text { erable Creep/d }\end{array} \\
\text { 3 }\end{array}$} & \multirow{2}{*}{$\begin{array}{c}\begin{array}{c}\text { Recoverable Creep Val- } \\
\text { ue/10-6/MPa }\end{array} \\
3.5\end{array}$} & \multicolumn{2}{|c|}{ Fitted Parameters } & \multirow{2}{*}{\begin{tabular}{|c}
$\begin{array}{c}\text { Loading Duration Incre- } \\
\text { ment for Unrecoverable } \\
\text { Creep/d }\end{array}$ \\
90
\end{tabular}} & \multirow{2}{*}{$\begin{array}{c}\begin{array}{c}\text { Unrecoverable Creep } \\
\text { Value } / \mathbf{1 0}^{-6} / \mathbf{M P a}\end{array} \\
9.9\end{array}$} & \multicolumn{2}{|c|}{ Fitted Parameters } \\
\hline & & $A_{0}$ & 2 & & & $D$ & 20 \\
\hline 7 & 5.1 & $A_{1}$ & 18 & 120 & 10.9 & $m_{3}$ & 0.01813 \\
\hline 10 & 5.7 & $A_{2}$ & 0.55 & 150 & 11.3 & & \\
\hline 15 & 6.1 & $B_{0}$ & 3 & 200 & 11.9 & & \\
\hline 30 & 7.4 & $B_{1}$ & 10 & & & & \\
\hline 45 & 8 & $B_{2}$ & 0.8 & & & & \\
\hline \multirow[t]{2}{*}{60} & 8.8 & $m_{1}$ & 0.06 & & & & \\
\hline & & $m_{2}$ & 0.2 & & & & \\
\hline
\end{tabular}

Table 1. Measured data and fitted creep parameters from concrete creep loading tests for sample C40, age: $7 \mathrm{~d}$.

Table 2. Measured data and fitted creep parameters from concrete creep loading tests for sample C40, age: 28d. 
where, $T$ is the temperature rise variable; $T_{0}$ is the ultimate temperature rise value; $T_{\mathrm{e}}$ is the early stage temperature rise value; $T_{1}$ is the mature temperature rise value; $a, b, c$ and $d$ are the test parameters. As for high strength concrete C40, $T_{0}$ $=26.4^{\circ} \mathrm{C}, T_{\mathrm{e}}=5^{\circ} \mathrm{C}, T_{1}=25^{\circ} \mathrm{C}, a=0.252, b=0.883, c=$ $0.005, d=0.252$.

These models' comparison is given in Fig. (5). According to Fig. (5), it can be deduced that the temperature rise values computed from those models converge at mature stage and the obvious discrepancy just lives at the early stage of hydration heat development.

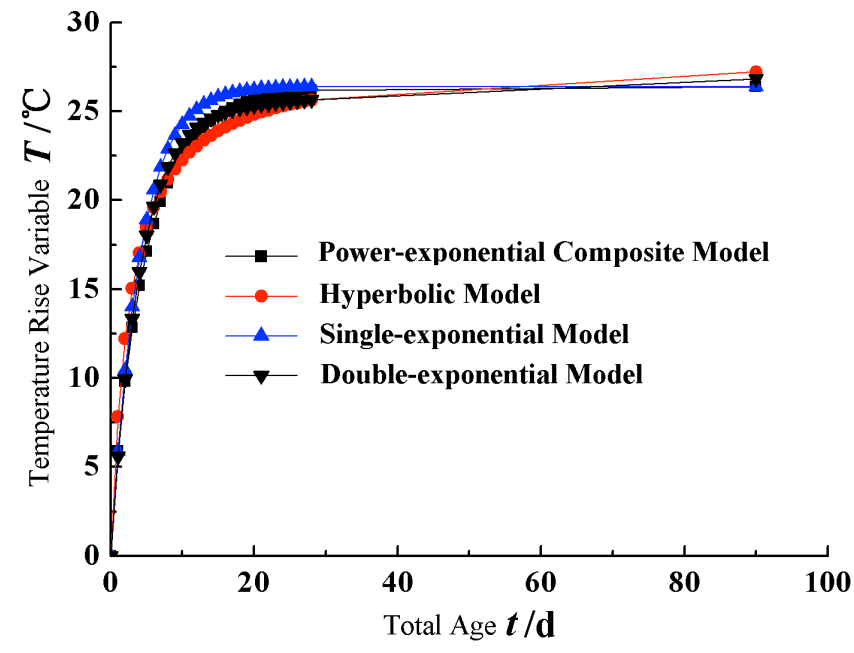

Fig. (5). Temperature rise models.

However, the fatal danger of thermo-dynamic fracture is often incurred at the early pouring stage of massively high strength concrete. Hence, the fly-ash powder is the indispensable constituent of the high strength concrete. It can reduce the hydration heat at the early stage of concrete pouring procedure (D. G. Snelson and J. M. Kinuthia, 2010; D. Krizan and B. Zivanovic, 1997) [7, 8].

\section{STRESS CHARACTERISTICS OF HIGH STRENGTH HYDRAULIC CONCRETE}

Stress characteristics analysis is also beneficial for deep insight into high strength hydraulic concrete research. Stress overloading is the main cause of hydraulic concrete material's failure (G. Habert et al., 2012; S. A. kumar and A. Veeraragavan, 2011) [9, 10].

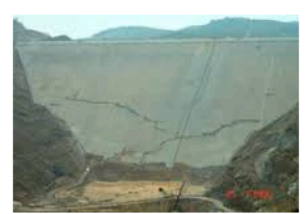

(a)

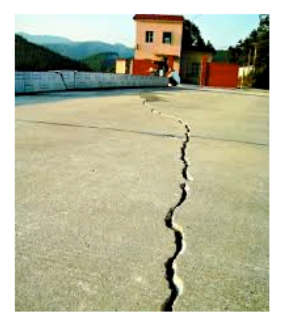

(c)

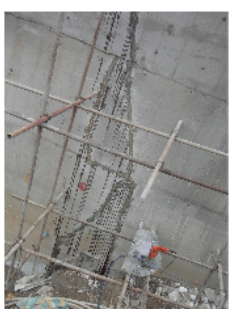

(b)

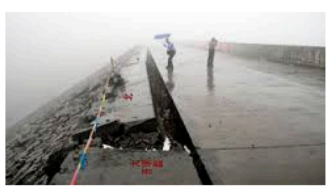

(d)
Fig. (6). Engineering cases on concrete cracks.

Stress development behaviors, whatever under static conditions or dynamic ones, control the reliability of most hydraulic structures (Fig. 6 where, (a) are the penetrated cracks in concrete gravity dam due to seismic stress development; (b) are the aged cracks on the surface of concrete arch dam due to static stress accumulation; (c) are the extending cracks in the shoulder of concrete face dam due to static stress accumulation; (d) are the eroded cracks in the crest of concrete face dam due to hydrodynamic stress development).

How to express the stress development behaviors of high strength hydraulic concrete? Strain-stress constitution on concrete plays the primary role in translating material's reliability and mechanical behavior (A. Turatsinze and M. Garros, 2008; A. Nazari and S. Riahi, 2011) [11, 12]. It is also the bases for other advanced technical models. Multi-axial compression loading tests were applied for the target high strength hydraulic concrete material. Multi-axial compression loading tests include uniaxial and biaxial compression loading tests.

The tensiometers are the key supplementary units in these tests to help get the complete strain-stress constitutional curves (Fig. 7 where (a) is instron multi-axial loading system; (b) is uniaxial compression loading case and the red

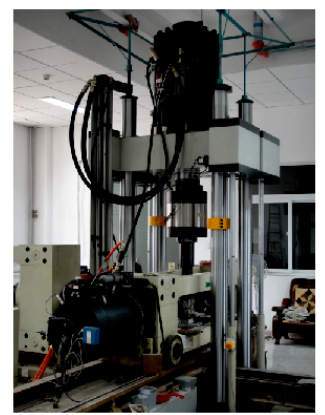

(a)

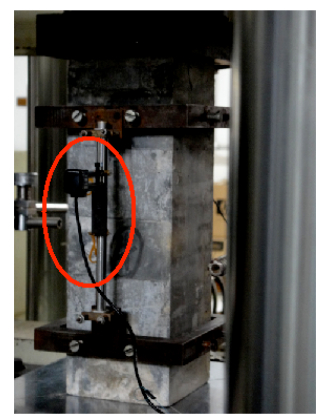

(b)

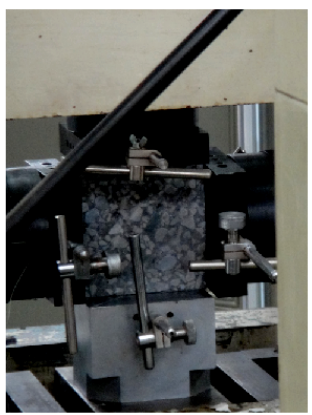

(c)

Fig. (7). Multi-axial compression loading tests. 

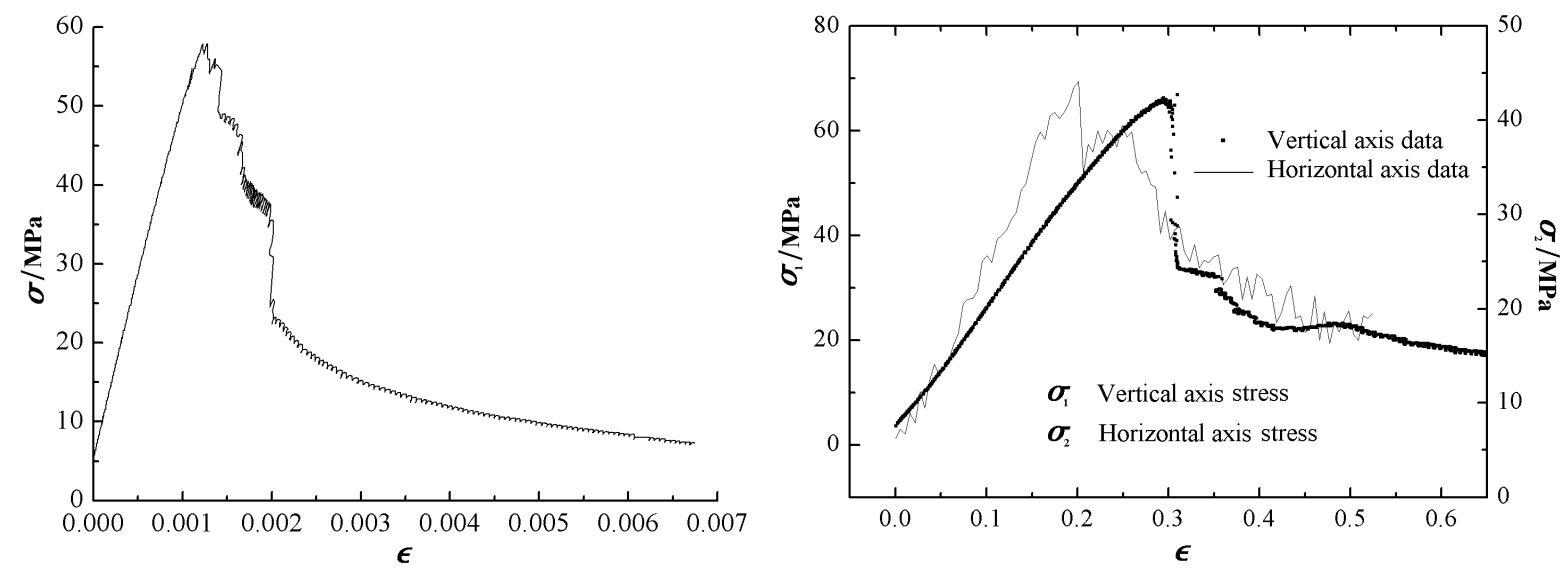

Fig. (8). Strain-stress curves from multi-axial compression loading tests.

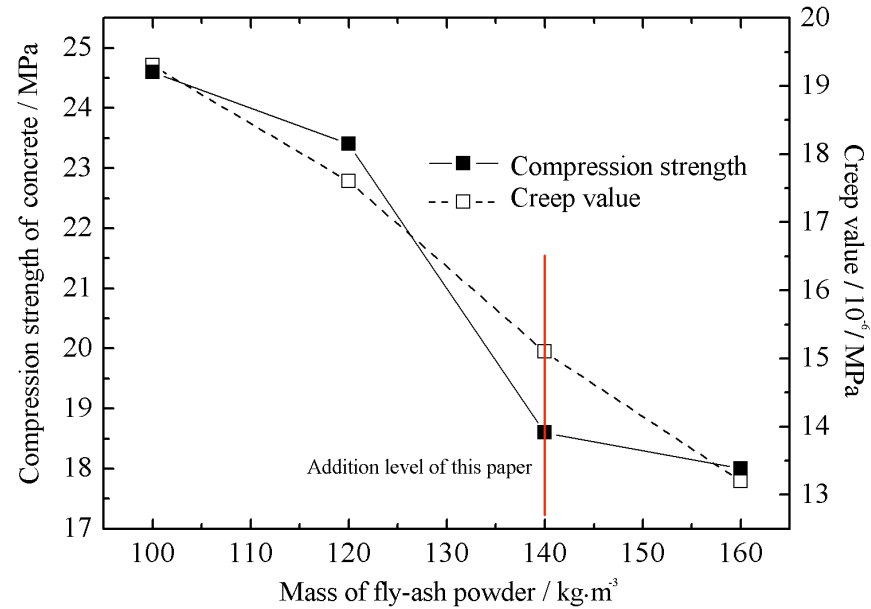

(a) Fly-ash powder

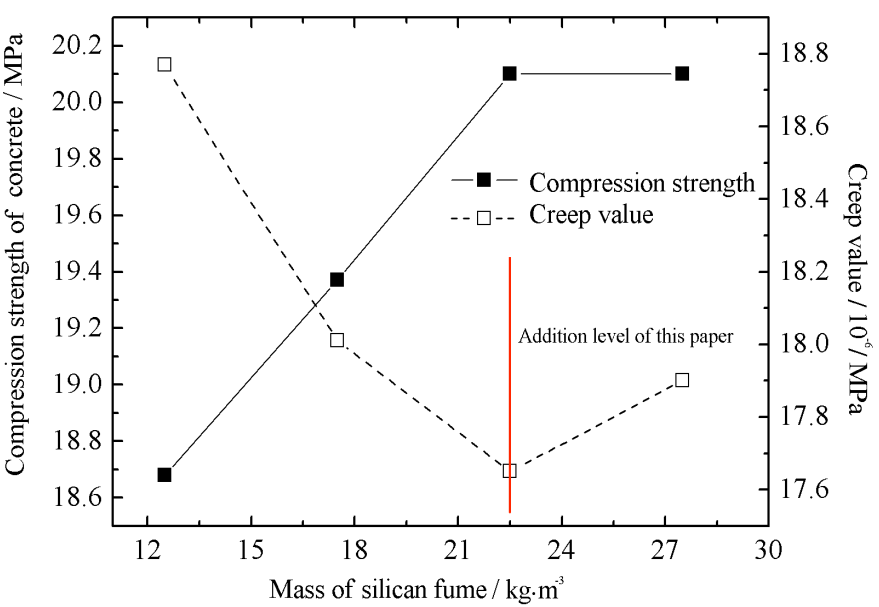

(b) Silica fume

Fig. (9). Concrete characteristics sensitivity to constituents' addition.

Table 3. Reference values for concrete constitution parameters.

\begin{tabular}{|c|c|c|c|c|c|c|}
\hline$\varepsilon_{f}$ & $\alpha_{1}$ & $\alpha_{2}$ & $\beta_{1}$ & $\beta_{2}$ & $\eta$ & $E_{\hat{o}} / \mathrm{MPa}$ \\
\hline \hline $1.23 \times 10^{-3}$ & $1.57 \times 10^{-1}$ & $8.43 \times 10^{-1}$ & 5.39 & 1.66 & 3.47 & $5.58 \times 10^{4}$ \\
\hline
\end{tabular}

circle area is the tensiometer; (c) is biaxial compression loading case.).

The strain-stress curves from both uniaxial and biaxial compression loading cases show that the mechanical behavior of the target high strength hydraulic concrete complies with non-linear constitutional model. The values of ultimate strength of uniaxial and biaxial compression loading cases are different ones. The vertical axial ultimate strength of biaxial compression loading case is $10 \mathrm{MPa}$ averagely higher than the one of uniaxial compression loading case. However, the horizontal axial ultimate strength of biaxial compression loading case is $14 \mathrm{MPa}$ averagely lower than the one of uniaxial compression loading case. Fig. (8) clearly shows all these characteristics.

In Sino-mainland, the generally accepted strain-stress constitution model for concrete is the bisection non-linear model which can be expressed as the Eq. 6 .

$$
\sigma= \begin{cases}{\left[1-\alpha_{1}\left(\frac{\varepsilon}{\varepsilon_{f}}\right)^{\beta_{1}}\right] E_{\hat{o}} \varepsilon} & 0 \leq \varepsilon \leq \varepsilon_{f} \\ {\left[\frac{\alpha_{2}}{\eta\left(\frac{\varepsilon}{\varepsilon_{f}}-1\right)^{\beta_{2}}+\frac{\varepsilon}{\varepsilon_{f}}}\right] E_{\hat{o}} \varepsilon} & \varepsilon>\varepsilon_{f}\end{cases}
$$

where, $\sigma$ and $\varepsilon$ are the stress and strain variables respectively; $\varepsilon_{f}$ is the ultimate strain of concrete under compression loading case; $\alpha_{1}, \alpha_{2}$ and $\beta_{1}$ are the concrete material parameters that indicate the continuousness of the bisection non-linear model at $\varepsilon_{f} ; \beta_{2}$ and $\eta$ are the shape parameters that indicate the geometrical characteristics of the non-linear strain-stress curves; $E_{\hat{o}}$ is the nominal modulus. The reference values of these parameters are shown in Table 3 . 


\section{DISCUSSION}

The study on characteristics sensitivity is valuable for ascertaining the effects of constituents' application in high strength hydraulic concrete. The study is based on internal addition method, namely, the cement was replaced by agents such as, fly-ash powder and silica fume, directly and variably. Fly-ash powder and silica fume are the main targets to be researched for their effects (Fig. 9). The compression strength of the concrete material will go lower with the increase of fly-ash addition level. By contrast, its creep values will run lower, too. The compression strength of the concrete material will grow with the increase of silica fume addition level. However, the increasing effect tends to converge. By contrast, its creep values will reach on peak with the increase of silica fume addition level.

\section{CONCLUSION}

High strength hydraulic concrete constituents were introduced. Thermo-dynamic characteristics can be expressed with creep models and temperature rise models. They are helpful for the quantification of the concrete material's temperature cracks hazard. The bisection non-linear model can explain the intrinsic non-linearity of strain-stress constitution of high strength hydraulic concrete. The proper addition of fly-ash powder and silica fume is the effective approach to improve the strength of hydraulic concrete.

\section{CONFLICT OF INTEREST}

The authors confirm that this article content has no conflict of interest.

\section{ACKNOWLEDGEMENTS}

This work was supported by the National Natural Science Foundation of China (Grant No: 51109118), Zhejiang Provincial Natural Science Foundation of China (Grant No: LY14E090001), United Development Project Foundation from Zhejiang Ocean University and Wenzhou University (Grant No: 21188004113), United Development Project
Foundation from Zhejiang Ocean University and Hydrochina Huadong Engineering Corporation (Grant No: 21188004013) and Young Teachers Improvement Project Fund of Zhejiang Ocean University (Grant No: 11042101512).

\section{REFERENCES}

[1] M. Bravo, and J. de Brito, "Concrete made with used tyre aggregate: durability-related performance", Journal of Cleaner Production, vol. 25, pp. 42-50, 2012.

[2] J. S. Ryou, and Y. S. Lee, "Properties of early-stage concrete with setting-accelerating tablet in cold weather", Materials Science and Engineering, vol. A 532, pp. 84-90, 2012.

[3] X. Y. Wang, "Evaluation of compressive strength of hardening silica fume blended concrete", Journal of Material Science, vol. 48, pp. 5953-5961, 2013.

[4] M. Nili, and V. Afroughsabet, "The long-term compressive strength and durability properties of silica fume fiber-reinforced concrete", Materials Science and Engineering, vol. A 531, pp. $107-$ $111,2012$.

[5] Q. Wang, J. J. Feng, and P. Y. Yan, "An explanation for the negative effect of elevated temperature at early ages on the late-age strength of concrete", Journal of Material Science, vol. 46, pp. 7279-7288, 2011.

[6] Z. W. Li, J. Y. Xu, and E. Baia, "Static and dynamic mechanical properties of concrete after high temperature exposure", Materials Science and Engineering, vol. A 544, pp. 27-32, 2012.

[7] D. G. Snelson, and J. M. Kinuthia, "Characterisation of an unprocessed landfill ash for application in concrete", Journal of Environmental Management, vol. 91, pp. 2117-2125, 2010.

[8] D. Krizan and B. Zivanovic, "Resistance of fly ash cement mortars to sulphate attack," In: Proceeding of the $10^{\text {th }}$ International Congress on Cement Chemistry, Gothenburg, paper 4iv020, 1997.

[9] G. Habert, D. Arribe, T. Dehove, L. Espinasseb, and R. L. Roy, "Reducing environmental impact by increasing the strength of concrete: quantification of the improvement to concrete bridges", Journal of Cleaner Production, vol. 35, pp. 250-262, 2012.

[10] S. A. Kumar, and A. Veeraragavan, "Dynamic mechanical characterization of asphalt concrete mixes with modified asphalt binders", Materials Science and Engineering, vol. A 528, pp. 6445-6454, 2011.

[11] A. Turatsinze and M. Garros, "On the modulus of elasticity and strain capacity of self-compacting concrete incorporating rubber aggregates", Resources, Conservation and Recycling, vol. 52, no. 10, pp. 1209-1215, 2008.

[12] A. Nazari and S. Riahi, "Improvement compressive strength of concrete in different curing media by $\mathrm{Al}_{2} \mathrm{O}_{3}$ nanoparticles", Materials Science and Engineering, vol. A 528, pp. 1183-1191, 2011. 